\title{
A POLÍTICA EXTERNA DE RIO BRANCO
}

\author{
Luciano da Rosa Muñoz ${ }^{1}$
}

\begin{abstract}
Resumo
Este artigo pretende analisar as concepções de Rio Branco no que diz respeito à política externa brasileira no começo do século $\mathrm{XX}$, período durante o qual esteve à frente do Ministério das Relações Exteriores por quase uma década. Em primeiro lugar, o artigo apresenta algumas definições teóricas com respeito às relações internacionais, bem como características da sociedade global que emergiu do Congresso de Viena. Dentro deste contexto, o artigo resume as principais características da história brasileira na virada do século XIX. Na seqüência, descreve brevemente alguns fatos da vida de Rio Branco, bem como analisa as três dimensões de sua política externa, isto é, a política territorial, as relações com os vizinhos e as relações com as grandes potências. Na questão territorial, o artigo enfatiza os objetivos alcançados por Rio Branco, o qual liderou todas as negociações sobre uma base pacífica e diplomática. No concernente à vizinhança, o artigo indica a cordialidade como o leitmotiv das ações de Rio Branco, o qual objetivou a estabilidade política e institucional da América do Sul. Com respeito às relações com as grandes potências, Rio Branco tentou salvaguardar a soberania brasileira o máximo possível, perseguindo um papel ativo para o país no cenário internacional daquela época. Finalmente, o artigo delineia conclusões apontando algumas implicações teóricas a fim de se analisar os propósitos de Rio Branco.
\end{abstract}

\section{Palavras-chave}

Política externa brasileira; Rio Branco; relações internacionais.

\section{Abstract}

This paper intends to analyze Rio Branco's conceptions regarding the Brazilian foreign policy in the beginning of the twentieth century, period during which he was ahead of the Ministry of External Relations for almost a decade. In the first place, the paper presents some theoretical definitions with respect to international relations as well as

${ }^{1}$ Luciano da Rosa Muñoz é bacharel em Direito e Licenciado em História pela Universidade Federal de Pelotas, RS. Atualmente é mestrando em Relações Internacionais pela Universidade de Brasília (UnB). 
features of the global society that grew up from the Vienna Congress. Within this context, the paper summarizes the main characteristics of the Brazilian history in the turning of the nineteenth century. Afterwards, the paper briefly describes some of the facts of Rio Branco's life as well as analyzes the three dimensions of his foreign policy, that is, the territorial policy, the relations with the neighbors and the relations with the great powers. On the territorial issue, the paper emphasizes the goals accomplished by Rio Branco, who led all the negotiations on a peaceful and diplomatic basis. Concerning the neighborhood, the paper indicates the cordiality as the leitmotiv of Rio Branco's actions, who aimed the South America's political and institutional stability. Regarding the relations with the great powers, Rio Branco tried to safeguard the Brazilian sovereignty the most possible, pursuing an active role for the country in the international scene of that time. Lastly, the paper draws conclusions pointing some theoretical implications in order to analyze Rio Branco's purposes.

\section{Keywords}

Brazilian foreign policy; Rio Branco; international relations.

\section{Definições conceituais}

Conforme Aron (1986, p. 153), sistema internacional "é o conjunto constituído pelas unidades políticas que mantêm relações regulares entre si e que são suscetíveis de entrar numa guerra geral". No tocante à correlação de forças dentro do sistema, o autor propõe duas categorias. De um lado, estão os sistemas bipolares, nos quais duas unidades políticas superam todas as demais em importância. De outro, aparecem os sistemas multipolares, dentro dos quais há várias unidades políticas que gozam do mesmo peso, o que torna possível a existência de diversas alianças entre as mesmas. Além disso, poderão os sistemas ser heterogêneos, quando as unidades políticas apresentam valores contraditórios, sendo organizadas de forma distinta, ou homogêneos, quando os Estados comungam as mesmas concepções políticas. Para Aron (1986), os sistemas homogêneos possuem maior estabilidade.

Na visão de Watson (1992), as relações internas a um sistema de Estados podem ser classificadas em quatro espécies. No estágio das múltiplas independências, os Estados possuem autonomia nas decisões de política interna e externa. Nesta espécie, porém, haverá uma propensão à hegemonia. Nesta última, um ou mais Estados determinam 
as relações externas dos demais, embora os deixando livres no âmbito doméstico. Em caso de domínio, uma autoridade central influi na determinação do governo dos demais membros do sistema, porém estes mantêm sua identidade e alguma autonomia nos negócios internos. Na fase de império, um Estado impõe aos demais sua administração direta, organizando seu poder através de círculos concêntricos. Haverá controle direito no centro, ao passo que nas faixas periféricas haverá regiões de domínio, hegemonia e de Estados independentes vizinhos. No caso de império, há propensão à autonomia.

Na concepção de Duroselle (2000, p. 398), uma potência é um Estado capaz de "modificar a vontade de indivíduos, grupos ou Estados estrangeiros". A grande potência terá à sua disposição meios de convencimento pacíficos, como a negociação e a persuasão, e belicosos, como a ameaça e o uso da violência. De seu lado, a pequena potência disporá apenas dos primeiros expedientes citados, podendo se utilizar dos demais em três situações, vale dizer, quando for apoiado por potências maiores, em um conflito localizado ou em uma guerra de subversão. Consoante Morgenthau (apud Nogueira; Messari, 2005), todos os Estados têm o poder como principal objetivo. Este pode dar-se pela busca da manutenção do status quo, da expansão ou do prestígio. Consiste este último na capacidade de o Estado impressionar os demais com o próprio poder, seja pela diplomacia, seja pela força.

\section{Aspectos contextuais}

O contexto global dentro do qual o Barão do Rio Branco exerceu suas atividades diplomáticas é o que Hobsbawm (1988) chama de Era dos Impérios (1875-1914). Trata-se de um período de formação de grandes impérios coloniais encabeçados pelas potências européias, especialmente após o famigerado Congresso de Berlim (1885), que determinou a partilha da África. 0 final do século XIX marca a emergência de duas grandes potências, a saber, Estados Unidos e Alemanha, que começam a rivalizar com a Inglaterra. Este país, pioneiro na Revolução Industrial, possuía, na primeira metade do século XIX, supremacia inconteste no mundo capitalista, sobretudo após a derrota napoleônica e o Congresso de Viena (1815). Como salienta Magnoli (1997), neste momento ocorreu a estabilização do sistema europeu de Estados em torno de uma geometria pentagonal (Inglaterra, França, Áustria, Prússia e Rússia). Após a independência (1822), a Inglaterra era o pólo de atração da política externa brasileira. 
Como pondera Watson (1992), após o Congresso de Viena firmou-se no continente europeu uma hegemonia difusa entre aquelas cinco potências, no que ficou conhecido como Concerto Europeu. Até a Primavera dos Povos (1848), o Concerto perpetrou intervenções em outros países europeus, gerando a independência da Bélgica e governos liberais em Espanha e Portugal. Não obstante, a partir desta data ocorreu o recrudescimento das tendências nacionalistas e revolucionárias. Neste momento, o grande perigo para o Concerto era o pangermanismo e a possibilidade de surgimento de uma poderosa nação conglobando grande população de fala alemã. Dessa forma, a unificação alemã (1871) marcou o início da ascendência de Bismarck sobre a Europa, embora evitando chocar-se com Rússia e Inglaterra, como desastradamente fizera Napoleão. Com a queda do chanceler de ferro em 1890, no entanto, a Alemanha, já visivelmente uma grande potência, incrementou o nacionalismo, gerando a aliança antihegemônica entre França e Rússia.

De sua parte, os Estados Unidos aumentaram sobremodo seu desenvolvimento econômico após a Guerra Civil (1861-65), o que gerou enorme corrente migratória àquele país. Além disso, lançaram-se em uma política imperialista, sobretudo a partir do final do século XIX, quando derrotaram a Espanha na chamada Guerra Hispano-americana (1898), aumentando sua ascendência sobre Cuba e anexando Porto Rico, Guam e Filipinas. Neste mesmo ano, ainda houve a anexação do Havaí. Como constata Bueno (2003), as grandes empresas norteamericanas, pressionadas pelas leis antitrustes, expandiram seus capitais para o exterior. O Tratado Hay-Paucefote (1900) dava aos Estados Unidos o controle do canal que fosse eventualmente construído no Panamá. No início do século XX, o presidente Theodore Roosevelt reeditou a Doutrina Monroe e o Destino Manifesto. Assim, a primeira, que foi lançada originalmente em 1823 com propósitos defensivos, como dissuasão à Santa Aliança, foi transformada pelo Corolário Roosevelt (1904) em justificativa para o intervencionismo na América Latina.

No final do século XIX, o Brasil enfrentava mudanças, com a Abolição da escravatura (1888) e a Proclamação da República (1889). Na visão de Burns (2003), este último evento marcou o reconhecimento do café como principal produto da economia brasileira, acabando com a aliança tradicional entre a monarquia e os interesses açucareiros. Não obstante, como salientam Cervo e Bueno (2002), as potências européias recalcitraram em reconhecer o novo regime. Na imprensa londrina, era ruim a imagem do Brasil, em razão das reformas econômicas de Rui 
Barbosa, no episódio conhecido como "Encilhamento", e da crise entre Deodoro da Fonseca e o Congresso Nacional, temendo-se o início de uma era de pronunciamentos no país. Com efeito, foram de fato convulsionados os primeiros anos da República. Nesse sentido, salientam aqueles autores que a política externa brasileira do período 1889-1902 não teve uma diretriz determinada, já que se sucederam 11 ministros de relações exteriores neste curto lapso temporal.

A República nascente foi marcada por um americanismo idealista, em oposição direta ao europeísmo monárquico. Dentro desse espírito de fraternidade americana, o chanceler Quintino Bocaiúva negociou com Estanislau Zeballos, seu par argentino, a divisão do território de Palmas (1890), localizado a oeste de Santa Catarina, contrariando a visão mais realista do Império, que pretendia submeter a questão a arbitramento internacional. Das gestões de Bocaiúva resultou o Tratado de Montevidéu, que acabou sendo rejeitado no Parlamento. Posteriormente, em 1895, o Brasil ganharia o domínio sobre tal área, com a arbitragem favorável do presidente norte-americano Grover Cleveland, o que constituiu a primeira grande vitória de Rio Branco em questões territoriais. Em 1900, após o laudo arbitral favorável do presidente da Confederação Suíça, Paranhos teria novo êxito, com o Brasil incorporando a região do Amapá, então reivindicado pela França. Na Conferência de Washington (1889), primeira de uma série em que os Estados Unidos procurariam utilizar a concepção de pan-americanismo para angariar vantagens comerciais no continente, o chanceler Salvador de Mendonça inverteu a orientação imperial, pondo-se em completo acordo com aquele país.

A influência norte-americana ficou patente por ocasião do Convênio firmado em 1891, pelo qual o trigo norte-americano ficou isento de qualquer tarifa, mantendo o café situação análoga no mercado consumidor dos Estados Unidos. No entanto, o açúcar acabou prejudicado com a posterior livre entrada concedida ao produto cubano. Ademais, quando ocorreu a Revolta da Armada (1893-94), que opôs a Marinha, que assumiu tom monarquista, e o Exército, representado pelo presidente Floriano Peixoto, decisiva foi a atuação da marinha norte-americana, que rompeu o bloqueio dos revoltosos, fortalecendo e garantindo o êxito deste último. 0 país entrou em um período de tranquilidade com a presidência de Rodrigues Alves (19021906), após a pacificação promovida por Prudente de Moraes, especialmente em Canudos, e a reabilitação financeira empreendida por Campos Sales. Esse período também marcou a primeira crise de superprodução do café, que acarretou o Convênio de Taubaté (1906), 
assinado pelos governos de São Paulo, Minas Gerais e Rio de Janeiro, com apoio do governo federal. Os governos compraram o excesso de café, visando à recuperação dos preços do produto. Igualmente, tentouse desestimular plantações de novos cafezais.

Além disso, o início do século XX marcou o boom da produção de borracha, a qual alcançou 39\% das exportações nacionais em 1910. Como destaca Burns (2003), o produto contribuiu para a expansão territorial brasileira, com o aumento de seringais explorados na Amazônia. É atrás da borracha que grande número de brasileiros se instalaria no Acre, legitimando os direitos do Brasil sobre a região. Para Bueno (2003), o período compreendido entre 1900 e 1913 deve ser considerado a era de ouro da Primeira República, com o desempenho satisfatório do café, da borracha e com os investimentos europeus. Em 1902, os Estados Unidos consumiam 37,9\% da safra de café do Brasil, sendo os maiores importadores do país nesse período. Em razão do Convênio de 1891, o Brasil já comprava mais trigo norte-americano do que argentino. Por outro lado, a Inglaterra ainda era o país que mais exportava para o Brasil, pauta composta majoritariamente por manufaturados. Da mesma forma, os ingleses lideravam o volume de investimentos no Brasil.

\section{Concepções de Rio Branco}

Após um período inicial de instabilidade, o país passava por um momento de prosperidade com o governo de Rodrigues Alves (19021906). Seguindo o exemplo do Barão de Haussmann, que havia liderado a reforma da cidade de Paris na segunda metade do século XIX, Pereira Passos, prefeito do Rio de Janeiro, iniciou o embelezamento da cidade, do qual a abertura da Avenida Central foi o grande marco. Ao mesmo tempo, teve início uma campanha contra a insalubridade da capital federal, sob os auspícios do sanitarista Oswaldo Cruz, o qual pôs em prática uma ampla campanha de vacinação. Baseado na notoriedade alcançada por Rio Branco após os êxitos nas questões fronteiriças, o presidente Rodrigues Alves resolveu convidá-lo para a pasta de relações exteriores, depois de uma década de indefinição nos rumos da política externa brasileira. Rio Branco havia passado longos anos como Cônsul em Liverpool, cargo que assumiu em 1876. 
Neste período, Paranhos acumulou vastos conhecimentos de história e de geografia do país, disciplinas de sua maior predileção. Estes lhe foram de enorme valia na última década do século XIX, quando assumiu o posto de representante do Brasil na questão de Palmas, território reivindicado pela Argentina desde 1881, o qual criaria uma cunha estrangeira entre os estados de Santa Catarina e Rio Grande do Sul. Graças à competência de Rio Branco, que na ocasião derrotou o rival argentino Zeballos, pôde o Brasil ser vitorioso no laudo arbitral emitido pelo presidente norte-americano Grover Cleveland. Em razão disto, Rio Branco voltaria a defender os interesses do país na questão do Amapá, sendo novamente vitorioso e evitando que a França avançasse pela Amazônia. Emitido em 1900, este laudo arbitral garantiu aquele território ao Brasil, tendo sido proferido pelo presidente da Confederação Suíça. Estas conquistas diplomáticas lhe deram notoriedade, legitimando-o a ocupar a Chancelaria em dezembro de 1902.

Segundo salienta Bueno (2003), Rio Branco desfrutou de autonomia na condução da política externa, gozando de grande prestígio. 0 chanceler teve sua formação durante o Império, sendo filho de outro conhecido diplomata, o Visconde do Rio Branco. Não obstante, soube pôr em prática uma simbiose entre as tendências históricas da política externa imperial e as diretrizes republicanas, dando continuidade à postura pan-americana aprofundada após 1889. Quis exercer a grande politique, calcado na prosperidade da lavoura brasileira e na estabilidade das instituições políticas após Campos Sales. Paranhos, que viveu na Europa de 1876 a 1902, viu de perto o capitalismo industrial em sua etapa imperialista, receando por agressões à América Latina. Para ele, a melhor maneira de proteger-se era garantir a estabilidade política da região. Rio Branco queria aumentar o prestígio do Brasil, para que o país desempenhasse um papel de liderança no sul do continente, semelhante à ação dos Estados Unidos ao norte. Fato importante para o prestígio do país foi a criação do primeiro Cardinalato sul-americano no Rio de Janeiro (1905).

Consoante Lins (1965), Rio Branco retomou a tradição da política exterior do Império. Deve-se, porém, fazer uma ressalva. Não se pode afirmar que Rio Branco tencionava resgatar a atitude belicista esposada 
pelo Império em meados do século XIX, no período que se estende de 1851 a 1876. Durante este período, o exército imperial envidou esforços para a deposição dos aliados Oribe e Rosas, posteriormente voltando-se contra Solano López, já no contexto da Guerra do Paraguai. Como pondera Bandeira (2006), uma vez assegurada a tranquilidade interna do Império, o país voltou-se para o estabelecimento de sua hegemonia na bacia do Rio da Prata. Para tanto, contou com a colaboração de Mauá, tornando-se o patacão moeda corrente na região, com o qual o Brasil tornou o Uruguai e a Confederação Argentina financeiramente dependentes. Diferentemente, Paranhos procurou estabelecer um nível de cordialidade com os vizinhos, vendo o Brasil com uma possível garantia da paz e da estabilidade institucional da América do Sul. Nesse sentido, pode-se asseverar inclusive que Rio Branco visava à superação do passado turbulento do subcontinente, atento às investidas imperialistas do começo do século $\mathrm{XX}$, prenhes da retórica contra os chamados governos incompetentes das nações menos desenvolvidas.

Com efeito, pode-se considerar que Rio Branco procurou retomar a política externa imperial posterior a 1876. Como salientam Cervo e Bueno (2002), a partir deste momento iniciou-se um período de distensão nos atritos com os vizinhos, procurando o Brasil evitar a guerra com a Argentina. Além disso, o país deu ênfase ao universalismo, engajando-se no movimento pan-americanista, propalado pelos Estados Unidos. De sua parte, Dom Pedro II procurou pôr em prática uma diplomacia de prestígio, viajando pelo mundo e divulgando a imagem do país. Outro aspecto relevante, desta vez destacado por Almeida (2001), é a forte presença diplomática do país em todos os países importantes e em foros multilaterais relevantes, colocando-se o Brasil no plano das potências. Nesse sentido, Rio Branco aprofundou as relações com os Estados Unidos, porém despidas da visão idealista de Salvador de Mendonça e do início da República, quando se negociou o desvantajoso Acordo comercial de 1891. Assim, Paranhos retomou a visão circunspecta e pragmática dos diplomatas do Império em relação à nação norte-americana. Outro paralelo entre a orientação de Rio Branco e o período 1876-1889 é a política de prestígio, além da presença do país nos foros multilaterais, dos quais o mais reluzente foi a Conferência da Paz de Haia, em 1907. 
Como afirma Doratioto (2000), Rio Branco assumiu a Chancelaria quando o Brasil se encontrava isolado na América do Sul. No entanto, via o país em posição de destaque no subcontinente, em razão de sua dimensão territorial, condição econômica e situação geográfica. Antes, porém, o Brasil deveria superar entraves de sua posição internacional, como a reconquista de sua credibilidade após dez anos de conflitos internos, e a definição de suas fronteiras. Para tanto, como considera aquele autor, Rio Branco redirecionou a política externa brasileira da área de influência da Inglaterra para a dos Estados Unidos e aproveitouse das contradições entre essas potências, que disputavam a preponderância sobre a região. 0 chanceler preocupava-se com a estabilidade da América do Sul, tendo por intuito transformá-la em um espaço geopolítico de liderança brasileira. Na concepção de Ricupero (2000), a política externa de Rio Branco tinha três eixos, quais sejam, a política territorial, as relações assimétricas de poder com as grandes potências e as relações de relativa simetria com os vizinhos da América do Sul. Queria para o Brasil um papel de intermediário entre os Estados Unidos e a América Latina, aumentando o prestígio do país.

\section{A política territorial}

Segundo dados de Magnoli (1997), $2.079 \mathrm{~km}$ de fronteiras do país tiveram sua definição no período colonial. Durante o Império, foram fixados $7.948 \mathrm{~km}$ de fronteiras. Somente no período republicano, que corresponde ao trabalho de Rio Branco até 1912, a horogênese foi de $5.062 \mathrm{~km}$. No período colonial, foi fixada a díade territorial completa com o Suriname, por conta da Paz de Haia com a Holanda (1661), além de parte da fronteira com a Argentina, localizada no rio Uruguai, e com a Bolívia, no rio Guaporé. Em 1837, o Barão da Ponte Ribeiro retomou a linha de pensamento de Alexandre de Gusmão, por ocasião do tratado de Madri (1750), defendendo o uti possidetis, princípio pelo qual teria direito a determinado território o Estado que efetivamente o ocupasse. Em 1849, com o Visconde do Uruguai, consagrou-se definitivamente o uti possidetis de facto, em oposição ao uti possidetis de jure, defendido pelas repúblicas hispânicas com base no tratado de Santo Ildefonso, assinado pelas metrópoles ibéricas em 1777. A diplomacia brasileira desde logo passou a refutar tal tratado por ter sido ele preliminar e posteriormente anulado pelo tratado de Badajós (1801). 
Em 1851, foi fixada a fronteira com o Peru, com base no rio Javari. No mesmo ano, foi imposto ao Uruguai um tratado de fronteiras, pelo qual se lhe excluiu a navegação pela Lagoa Mirim. Neste momento, o Brasil negociava em situação vantajosa com o governo colorado, por ter intervindo contra Oribe e pelo auxílio financeiro ao Uruguai ter sido garantido por Mauá. Em 1859, sobreveio tratado de limites com a Venezuela. Após a Guerra do Paraguai (1864-70), o Brasil negociou um tratado em separado com o país derrotado, fixando os limites nos rios Paraná, Apa e Paraguai. Como salientado alhures, a fronteira com a Argentina só foi definitivamente delimitada em 1895, quando o Brasil saiu-se vitorioso na questão de Palmas. Por laudo arbitral exarado em 1900, igualmente exitoso, o país incorporou o Amapá, definindo os limites com a Guiana Francesa. Nestes dois últimos casos, como dito, teve destaque a ação de Rio Branco.

Consoante Ricupero (2000), quatro eram os princípios seguidos por Rio Branco em matéria territorial. Os tratados coloniais assinados entre Portugal e Espanha, notadamente os de Madri e de Santo Ildefonso, não passavam de indicações genéricas, devido ao fato de terem sido subsequentemente anulados. Em segundo lugar, propôs-se à defesa do princípio do uti possidetis. Além disso, recusavam-se as negociações multilaterais, preferindo-se o tratamento em separado com cada parte. Por fim, Paranhos aceitava o recurso à arbitragem somente se as negociações diretas restassem frustradas. A maior razão que levou Rodrigues Alves a convidar Rio Branco a ocupar a pasta das relações exteriores foi a chamada questão do Acre, que opunha Brasil e Bolívia em 1902, contando igualmente com a emergência de interesses norteamericanos. Até aquele momento, o Itamaraty tinha sido incapaz de dar solução à problemática. Rio Branco, de sua parte, já era extremamente conhecido por seus êxitos territoriais em Washington e em Berna.

Em 1867, dentro do contexto da Guerra do Paraguai, procurando manter a Bolívia afastada de uma possível aliança com Solano López, o Brasil negociou com este país o Tratado de Ayacucho, pelo qual reconhecia sua soberania sobre a região do Acre. No entanto, com o boom da borracha no último quartel do século XIX e com a grande seca ocorrida no Ceará na mesma época (1877-79), o território começou a receber levas de brasileiros, os quais passaram a dedicar-se a exploração dos seringais. Como salienta Lins (1965), no fim do século XIX a posição do chanceler Olinto de Magalhães era a mesma do Império, encarando a questão sob um viés puramente jurídico. Assim, conforme a letra do tratado de 1867, era boliviano o Acre, de maneira que a Chancelaria reconhecia a soberania da Bolívia, não considerando 
litigioso o território. Na opinião de Lins (1965), tal concepção era defasada, visto que o Acre não mais era uma região abandonada como em 1867, além do que desde então brasileiros lá viviam, tendo inclusive pegado em armas para defender a região.

Conforme destaca Bandeira (2000), em 1899 a imprensa dos estados do Amazonas e do Pará levantou rumores sobre um acordo entre Estados Unidos e Bolívia, pelo qual os bolivianos receberiam apoio norteamericano para defender seus direitos sobre os territórios do Acre, Purus e Iaco, por via diplomática ou mesmo em caso de guerra contra o Brasil. No mesmo ano, foi instalada a aduana boliviana de Puerto Alonso na região, a qual trouxe enormes prejuízos à receita do estado de Amazonas, taxando a borracha oriunda do Acre, em detrimento do porto de Manaus. Com apoio de Ramalho Júnior, presidente do estado, e dos comerciantes da capital, Luis Galvez proclamou a independência do Acre em 14 de julho de 1899, tornando-se seu primeiro presidente. Ainda que a população fosse quase totalmente brasileira, o Itamaraty não interveio, considerando que cabia à Bolívia debelar a revolta.

Em 11 de junho de 1901, pelo contrato Aramayo-Withridge, o Acre foi arrendado pelo governo da Bolívia ao grupo anglo-americano Bolivian Syndicate. Como considera Bandeira (2000), esse protocolo afigurou-se inquietante ao Brasil, na medida em que transformava o Syndicate em uma espécie de companhia privilegiada, como as chartered companies então existentes na África, uma vez que lhe outorgava a plenitude do governo civil no Acre, com direitos soberanos, que incluíam os de manter polícia e equipar uma força armada ou barcos de guerra, para a salvaguarda dos rios ou da ordem interna. Como se percebe, a situação naquela região era muito delicada para o Brasil. De um lado, havia os interesses de cidadãos brasileiros lá residentes. De outro, o arrendamento do Acre trazia sérias ameaças à soberania nacional, com uma companhia estrangeira incrustada na região amazônica, com amplos poderes de decisão. Pouco tempo antes, Rio Branco havia se esforçado por evitar maior penetração francesa no vale amazônico, sendo vitorioso na questão do Amapá.

Para agravar a situação, nova rebelião teve lugar no Acre, com Plácido de Castro tomando Puerto Alonso em 24 de janeiro de 1903. Diante deste quadro, Paranhos, recém empossado na Chancelaria, reveria completamente a posição até então adotada sobre a questão. Segundo destaca Heinsfeld (2003), a partir de então, o problema seria analisado por um critério geopolítico e estratégico, e não puramente jurídico. Para tanto, Rio Branco optou por proteger Castro e considerar litigioso o 
território acreano. As primeiras propostas do chanceler, que incluíam a compra e a permuta do território, foram rechaçadas pela Bolívia, que deslocava tropas para a região. Em fevereiro de 1903, no entanto, muito em razão da vitória de Castro, os bolivianos começaram a ceder, aceitando que o Brasil pacificasse o Acre. Neste momento, o Syndicate desistia do contrato de arrendamento, impossibilitado de dar-lhe execução devido ao conflito na região.

0 Brasil então indenizou o conglomerado estrangeiro, ficando Rio Branco livre para negociar separadamente com a Bolívia. Em 21 de março de 1903 assinou-se o modus vivendi, pelo qual o Brasil ocuparia o território litigioso até o acerto final. Finalmente, em 17 de novembro, sobreveio o tratado de Petrópolis, pelo qual o país incorporava 200.000 $\mathrm{km}^{2}$ ao seu território, em troca de $3.164 \mathrm{~km}^{2}$ cedidos à Bolívia, além de uma indenização de 2 milhões de libras esterlinas e a obrigação de construir a ferrovia Madeira-Mamoré, que daria a este país saída ao mar pelo Oceano Atlântico. Porém, nem todas as questões fronteiriças estavam resolvidas a essa altura. Quando o Brasil negociou o Tratado de Ayacucho (1867), a Bolívia tinha problemas lindeiros com o Peru, que também reivindicava uma extensa área, a qual incluía o Acre.

Enquanto Rio Branco negociava com a Bolívia, propôs o Peru uma negociação tríplice, desde logo refutada por Paranhos, fiel a seus princípios de tratar com os adversários em apartado. Em reação, tropas peruanas começaram a marchar para a região do Acre em 1904. Satisfeita a Bolívia com o tratado de Petrópolis, voltou-se Rio Branco para as tratativas com o Peru. Assim, em 12 de julho de 1904 foi firmado o modus vivendi, o qual estabeleceu um prazo máximo de 5 anos para o acordo definitivo. De sua parte, o Brasil aguardaria o deslinde do juízo arbitral entre Peru e Bolívia, incumbido à Argentina em 1902. Em 9 de julho de 1909, determinou o presidente argentino Figueroa Alcorta a divisão do território disputado por aqueles países, o que gerou veementes protestos na Bolívia. Neste mesmo ano, foi assinado o tratado de limites com o Peru, baseado no uti possidetis de facto. Dos $442.000 \mathrm{~km}^{2}$ reivindicados ao Brasil, os peruanos receberam apenas $39.000 \mathrm{~km}^{2}$.

\section{Relações com as grandes potências}

Como assinalado outrora, Rio Branco iniciou de forma incisiva a reorientação da política externa brasileira de Londres para Washington. Para Burns (2003), que inclusive refere-se a esse novo panorama como 
o de uma aliança não escrita entre Brasil e Estados Unidos, algumas razões podem explicar essa convergência. Em primeiro lugar, os norteamericanos eram os maiores clientes do Brasil, englobando produtos como café, borracha e cacau, sendo complementares as exportações de ambos os países. Situação diversa se passava com a Argentina, concorrente dos Estados Unidos na exportação de trigo. Além disso, havia uma série de razões políticas que levavam Rio Branco a buscar o entendimento com os Estados Unidos. Para além das similitudes dos regimes republicanos, Rio Branco temia as intrigas dos países hispânicos, com a exceção do Chile, tradicional aliado do Brasil.

0 aumento do prestígio do Brasil no exterior era objetivo primordial de Rio Branco, servindo para tal a aliança com os Estados Unidos, fortalecidos após a guerra contra a Espanha (1898). De sua parte, o Brasil fortaleceria sua posição face à Europa e melhoraria sua situação na América do Sul. Nesta região, o país contaria com o apoio moral ou ao menos a neutralidade dos norte-americanos nas disputas fronteiriças com os vizinhos. Ainda segundo Burns (2003), Rio Branco explorava a posição do Brasil como intermediário entre os Estados Unidos e a América Hispânica em benefício do Brasil. Com efeito, o Itamaraty servia de amortecedor entre a impopular política norteamericana no Caribe e as reações no mundo hispânico, em prol do prestígio do país. 0 autor ressalta, no entanto, que de maneira nenhuma pode se considerar Rio Branco um lacaio dos Estados Unidos. Pelo contrário, por vezes o chanceler discordava do Departamento de Estado. As relações com aquele país eram guiadas por grande pragmatismo, em benefício do Brasil.

Quando lançada, em 1823, a Doutrina Monroe não foi bem recebida pelas repúblicas hispânicas, tendo sido, no entanto, reconhecida pelo Brasil de imediato. Rio Branco manteve a interpretação multilateral que lhe davam os diplomatas do Império, para que o Brasil compartilhasse responsabilidades e benefícios com os Estados Unidos no continente. Trata-se do que Bueno (2003) denominou de condomínio oligárquico de nações. Com efeito, Rio Branco considerava que as principais repúblicas americanas, a saber, Estados Unidos, Brasil, México, Argentina e Chile, deveriam responsabilizar-se pela estabilidade institucional da região. Nesse sentido, Paranhos acolheu de bom grado o Corolário Roosevelt (1904), já que o Brasil não poderia ser considerado uma república mal governada e turbulenta sujeita a intervenções. Efetivamente, os Estados Unidos voltavam-se nesse momento principalmente para a América Central. 
Ilustrativo da amplitude então reconhecida ao monroísmo foi o bloqueio anglo-ítalo-alemão sobre a Venezuela, ocorrido em 1902. Nesta ocasião, as potências européias encamparam a alfândega venezuelana em razão do inadimplemento deste país sul-americano de empréstimos feitos. Ocorre que os países intervenientes reconheceram tacitamente a Doutrina Monroe, ao consultarem previamente os Estados Unidos acerca da invasão. Candente era a questão do imperialismo colonial europeu no início do século XX, de maneira que havia temores de que seria a América Latina o próximo local de expansão, após África, Ásia e Oceania. Escrevendo logo após o bloqueio à Venezuela, Bomfim (2005) denunciava a opinião corrente na Europa acerca das repúblicas latino-americanas. Esta as considerava nações turbulentas governadas por políticos invariavelmente ladrões, povoadas por preguiçosos, mestiços e bárbaros. Por trás das sentenças condenatórias e das justificativas pseudo-científicas da teoria das raças inferiores, reflete Bomfim, estavam ameaças veladas de intervenção e violação da soberania dos países latino-americanos. Daí resultava, na visão de Rio Branco, a grande valia do monroísmo como poder dissuasório de qualquer iniciativa européia de expansão sobre o continente americano.

Por ocasião do bloqueio à Venezuela, sobreveio o protesto argentino por meio da Doutrina Drago, que repudiava a cobrança compulsória das dívidas de um país soberano. Nesse ponto, Rio Branco endossou a posição dos Estados Unidos, não apoiando o chanceler argentino, visto que assim se daria guarida aos maus pagadores, categoria em que o Brasil não se enquadrava. As boas relações com os Estados Unidos ficaram patentes com o reconhecimento do Panamá, que proclamou sua independência face à Colômbia em 3 de novembro de 1903. De grande repercussão para as relações bilaterais foi a criação recíproca de Embaixadas em ambos os países, em 10 de janeiro de 1905. Saliente-se que esta foi a primeira Embaixada criada pelo Brasil, para a qual foi enviado Joaquim Nabuco como autoridade máxima. Nabuco discrepava de certa forma de Rio Branco, por ser mais ideológico, alinhando-se incondicionalmente com os Estados Unidos. Quanto a este país, possuía até aquele momento apenas uma Embaixada na América Latina, localizada no México. Outro fato que elevou o prestígio do país foi a realização da $3^{\text {a }}$ Conferência Pan-americana (1905) no Rio Janeiro, tendo comparecido pessoalmente o Secretário de Estado Elihu Root.

Consoante destaca Bueno (1995), tinha o Império Alemão pretensões territoriais sobre o continente americano no princípio do século XX. Com efeito, em razão de sua unificação tardia, encerrada apenas em 
1871, a Alemanha havia sido preterida na corrida imperialista no final do século XIX, assenhoreando-se somente de regiões marginais como as atuais Namíbia e Tanzânia. Dessa forma, a América do Sul se lhes afigurava como o único espaço remanescente para eventual expansão. Havia motivos fortes para o êxito da empreitada, visto que a Alemanha aumentava gradualmente sua influência comercial e financeira na região, emulando os Estados Unidos. Além disso, àquela época o contingente imigratório alemão no sul do país chegava a 300.000 habitantes, que procuravam manter os laços com o Reich. De sua parte, os Estados Unidos, interessados em minorar a ascensão alemã, procurava incutir no Brasil o chamado perigo alemão, alertando-o sobre as possibilidades de invasão.

É dentro deste contexto que ocorre, em 27 de novembro de 1905, o incidente da Panther. Oficiais alemães da canhoneira com esta denominação desembarcaram no litoral de Santa Catarina sem autorização das autoridades locais, para capturar um desertor. Rio Branco logo reagiu contra a violação da soberania brasileira, exigindo a entrega do fugitivo em caso de captura, estando mesmo disposto a capturar a canhoneira em caso contrário. Nessa ocasião, Rio Branco pôde por em prática a política externa de perfil alto que desejava para o Brasil. Como escreve Lins (1965), a norma de Paranhos era o tratamento em igualdade de condições com qualquer potência estrangeira. Assim, a Alemanha foi tratada com altivez, sem espaço para transigências. Rio Branco explorou a rivalidade entre este país e os Estados Unidos, ancorando na garantia da Doutrina Monroe e utilizando aquele incidente para aumentar o prestígio internacional do Brasil. A questão se encerrou satisfatoriamente, com a Alemanha externando sua amizade ao país, lamentando o episódio e prometendo a punição dos culpados em tribunais militares.

Momento importante da diplomacia de Rio Branco foi a $2^{\text {a }}$ Conferência da Paz de Haia, realizada em 1907. Naquela ocasião teve destaque Rui Barbosa, chefe da delegação brasileira, a partir de então conhecido como águia de Haia. Com efeito, Rio Branco pôde por em prática então algumas de suas concepções sobre a atuação do Brasil no cenário mundial como potência, dentro de uma política de prestígio e de liderança na América do Sul. Questão colocada em pauta naquela conferência foi a já aludida Doutrina Drago. Neste ponto, o país seguiu os Estados Unidos, refutando a posição da diplomacia argentina. Como relata Lins (1965), Rui Barbosa teceu um engenhoso argumento jurídico acerca da questão. Segundo ele, não haveria violação de soberania pela cobrança coercitiva de dívidas pelo Estado credor, visto 
que quando contrata o empréstimo o Estado devedor estaria a agir como ente privado.

Conforme informa Burns (1985), as potências mundiais propuseram em Haia a criação de uma Corte Internacional de Justiça, na qual nove nações teriam assento permanente, dentre elas Estados Unidos, Inglaterra e Alemanha. As demais partilhariam as oito vagas restantes em um sistema de rodízio e conforme a categoria em que estivessem classificadas. Contra isto se insurgiu o Brasil, colocado na terceira categoria, abaixo de Estados europeus menores e menos populosos, considerando a proposta humilhante à dignidade nacional. Este seria o grande momento do Brasil em Haia. A oposição ao plano da Corte levou Rui Barbosa, previamente instruído por Rio Branco, a defender a tese da igualdade dos Estados livres e soberanos, com o que o Brasil surgiu não somente como líder das nações latino-americanas, delas recebendo amplo apoio, senão também de várias nações européias menores.

\section{Relações com os vizinhos sul-americanos}

De 1822 até 1828, ativa foi a política externa do Império com relação à região platina. A partir de 1825 , envolveu-se em uma guerra com as Províncias Unidas, pela posse da chamada Banda Oriental, a qual viria a dar origem ao Uruguai em 1828, muito em função dos esforços diplomáticos da Inglaterra. Desta data até 1843, a diplomacia imperial enfatizou a neutralidade do Brasil, máxime em razão das turbulências internas oriundas do período regencial. A partir de então, o Império começou a pôr em prática uma política externa mais altaneira, buscando a autonomia alfandegária, sobremodo com a tarifa Alves Branco (1844), que pôs fim aos tradicionais benefícios tarifários ingleses. Da mesma forma, o país voltou suas atenções para a bacia do rio da Prata, procurando impedir o expansionismo de Rosas, governante federalista da província de Buenos Aires. Como refletem Cervo e Bueno (2002), diversos eram os interesses do Brasil naquela região. Em primeiro lugar, os de ordem econômica, dentre eles o abastecimento de charque e os investimentos de Mauá. Além disso, havia razões estratégicas, pois o Império constituiu-se em arauto da independência de Paraguai e Uruguai contra possível avanço argentino.

Dessa forma, após a batalha de Monte Caseros (1852), as tropas imperiais, em aliança com o caudilho de Entre-Ríos Justo Urquiza, depuseram Rosas. No mesmo contexto, investiram contra os blancos de Oribe no Uruguai. Deste cenário, o Brasil emergiu como potência na 
região. Agregou-se a isto a vitória brasileira, dentro da Tríplice Aliança, contra o Paraguai de Solano López (1864-70). Isto tudo leva aqueles autores a afirmarem que o país estabeleceu uma hegemonia periférica na ótica do sistema internacional, durante os anos de 1851 e 1876. Após isto, o Brasil iniciou uma política de distensão na região, muito em função do início da crise interna que corroeria o regime imperial. Fato importante a ser destacado é a emergência do Chile neste período como potência regional. Nesse sentido, este país saiu extremamente fortalecido após a Guerra do Pacífico (1879-81), quando derrotou Peru e Bolívia coligados, subtraindo a esta a saída pelo Oceano Pacífico. Assim, o Império tornar-se-ia então o aliado preferencial do Chile, tendo-se em vista a impossibilidade de conflitos fronteiriços entre ambos e as prevenções comuns em relação à Argentina.

Após 1889, chanceleres como Quintino Bocaiúva e Salvador de Mendonça passaram a encarar as repúblicas vizinhas sob um prisma idealista, de fraternidade americana. Paradigmáticas neste sentido foram as concessões feitas pelo primeiro à Argentina na questão de Palmas, como já apontado alhures. Como escreve Bueno (2003), este país teve um grande crescimento econômico no período entre 1860 e 1910, somente comparável com o dos Estados Unidos. Foi um período de intenso aporte de capital inglês e de correntes migratórias maciças. No princípio da gestão Rio Branco, eram cordiais as relações entre os dois países, sobretudo devido ao presidente argentino Júlio Roca, que havia trocado visitas oficiais com Campos Sales. A rivalidade entre os vizinhos ressurgiu por ocasião do plano de rearmamento naval do Brasil, aprovado em 1906, e da criação da Embaixada brasileira em Washington. Quanto às forças navais, ressalte-se que o Brasil havia perdido a primazia na região após a Revolta da Armada. Além disso, candente na época era a questão do poder naval, principalmente após a vitória do Japão sobre a Rússia em 1905.

As relações bilaterais ficaram especialmente tensas após 1906, quando Estanislau Zeballos assumiu a Chancelaria argentina. Possuía sérias desconfianças quanto a um hipotético expansionismo brasileiro, além de ressentimentos pessoais em relação a Rio Branco, por ocasião do êxito deste na questão de Palmas. Parte da imprensa argentina denunciava a aliança entre Brasil e Estados Unidos, asseverando ser aquele um gendarme destes na América do Sul. Isso se explica, pois a Argentina procurava rivalizar com os norte-americanos no continente, concorrentes ademais na exportação de trigo. Para Zeballos, Rio Branco estaria querendo retomar a tradição expansionista do Império, no que estaria ameaçada a integridade territorial de seu país. Evidentemente, 
equivocada era esta concepção. Paranhos não tinha veleidades belicistas na região. Pelo contrário, pois sua maior preocupação era garantir a estabilidade da América do Sul, demovendo a opinião pública internacional da possível turbulência do subcontinente. Além disso, o rearmamento naval respondia a uma necessidade de segurança nacional, visando evitar agressões extracontinentais, em uma época em que o imperialismo atingia seu ápice.

A diplomacia argentina insistia em dois pontos. De um lado, exigia que o Brasil lhe concedesse as mesmas vantagens tarifárias outorgadas ao trigo norte-americano em 1906. Rio Branco manteve-se impassível, levantando como argumento em favor dos Estados Unidos sua condição de grande importador de café, categoria na qual não se enquadrava a Argentina. Outra questão de honra para Zeballos foi a da equivalência naval, visando tolher o poder de liberdade do Brasil em seu rearmamento. Novamente, Rio Branco recusou-se a submeter os interesses soberanos do país à vontade do chanceler argentino. Fato é que o Brasil receberia em 1910 os dois primeiros modernos dreadnoughts, que seriam, a propósito, palco para os marinheiros revoltosos no mesmo ano. Em reação, e comemorando o centenário de sua independência, a Argentina encomendaria dois navios do mesmo porte. 0 ano de 1908 marcou o apogeu das tensões entre os dois países. Zeballos repercutia na imprensa de seu país seu belicismo e acerbo antibrasileirismo. Tinha mesmo um plano de invasão do Rio de Janeiro se o Brasil não aceitasse a equivalência naval. Uma vez descoberto, acabou gerando sua demissão em 21 de junho de 1908 (Bueno, 2003).

Não satisfeito, Zeballos partiu para expedientes ilícitos para desmoralizar Rio Branco. No episódio do telegrama $n^{\circ}$ 9, o argentino interceptou mensagem entre Rio de Janeiro e Santiago, adulterando-lhe o conteúdo, a fim de divulgar na imprensa as inequívocas intenções agressivas de Paranhos, o que legitimaria sua diplomacia belicista. Ora, Rio Branco tornou pública a chave de decifração dos telegramas do Itamaraty e comprovou que o texto veiculado nada tinha a ver com o que afirmava Zeballos. De fato, eram frias as relações do Brasil com o governo Figueroa Alcorta, o qual não externou pêsames pelo falecimento de Joaquim Nabuco em 1910. Em 1909, imediatas foram as reações, quando o Brasil retificou suas fronteiras com o Uruguai, concedendo-lhe o condomínio da Lagoa Mirim e do Rio Jaguarão. Este ato foi visto pelo governo argentino como uma forma de Rio Branco aumentar sua ascendência sobre o Uruguai, justamente em um momento em que a Argentina mostrava-se intransigente na questão da jurisdição sobre as águas do rio da Prata. As relações bilaterais 
melhorariam apenas em 1910, com a eleição de Sáenz Peña na Argentina.

Em que pesem as diatribes da imprensa argentina e de Zeballos, Rio Branco, segundo considera Bueno (2003), não aspirava a qualquer política agressiva na América do Sul. Em realidade, pretendia para o Brasil o exercício de uma influência compartilhada no subcontinente. Notório a esse respeito foi o projeto do Tratado ABC, que englobaria Argentina, Brasil e Chile. Com este acordo, o qual acabaria sendo assinado somente após o falecimento de Rio Banco, em 1912, pelo chanceler Lauro Müller, Paranhos queria instaurar um clima de cordial inteligência entre as três grandes nações sul-americanas, para que estas fossem garantes da estabilidade na região, ameaçada nas repúblicas menores. Como destaca Ricupero (2000), tal coordenação seria complementar à aliança não escrita com os Estados Unidos. Em suma, Rio Branco não visava uma política intervencionista na região, como ocorrera no Império. Almejava uma situação de projeção mundial para o Brasil. Nesse período, igualmente importante era a estabilidade política e institucional da América do Sul, em meio às ameaças de agressão imperialista européia.

Como salienta Cervo (2008), um dos aspectos característicos da política externa desde o Visconde do Rio Branco foi o paradigma da cordialidade oficial com os vizinhos. Dentro dessa lógica, o primeiro Rio Branco procurou fundir a linha moderada, de nomes como Visconde de Abaeté, Marquês de Olinda e Visconde de Sinimbu, mais propensos à negociação e às soluções diplomáticas, com a corrente realista, seguida por Visconde do Uruguai, Marquês de Paraná e Barão de Cotegipe, favoráveis às saídas pela força. Em sua gestão, o segundo Rio Branco seguiu a lição do pai, fazendo prevalecer a cordialidade no trato com os países da América do Sul, almejando garantir a paz regional, em um período de conflitos interimperialitas. Escrevendo em 1905, Manoel Bomfim refletiu o difundido temor existente à época de que a próxima área de expansão européia fosse a América Latina. A partir disto podem ser explicados dois vetores da política externa de Rio Branco. De um lado, a já destacada preocupação com a estabilidade política e institucional da América do Sul, de maneira que fosse encarada como parte do mundo civilizado, não enquadrada em teorias racistas então em voga. De outra parte, a aproximação com os Estados Unidos, potencial aliado contra eventual investida européia. 


\section{Conclusão}

Com base nos aspectos teóricos e contextuais apresentados ao longo do presente artigo, algumas ilações podem ser feitas. Em primeiro lugar, pode-se afirmar que os objetivos perseguidos por Rio Branco em termos de política externa apontavam tanto para o sistema internacional, no âmbito das relações assimétricas com as potências, quanto para o subsistema sul-americano, na teia das relações simétricas com os vizinhos. No que tange à América do Sul, possível é asseverar-se que se configurava como um sistema homogêneo, pois formado apenas por repúblicas, e multipolar, na medida em que havia no limiar do século XX pelo menos três potências nesta região, quais sejam, Brasil, Argentina e Chile.

No que toca ao sistema internacional, ressaltou-se que um dos temas mais candentes à época de Rio Branco foi a questão do imperialismo. De sua parte, pode-se classificar o Brasil como pequena potência relativamente aos países mais influentes daquele período. Como se salientou, tal espécie de potência dispõe de meios não-pacíficos de convencimento em conflitos localizados e quando apoiado por potências maiores. Entretanto, considera-se que Rio Branco não buscou uma política agressiva para a América do Sul, dentro de uma lógica expansionista de estabelecimento de uma hegemonia com exclusão dos demais membros do subsistema. Tal subcontinente era composto por múltiplas independências. Assim, houve tendência à hegemonia de parte de Brasil, Argentina e Chile. Não obstante, considera-se que Paranhos visou encetar uma política de cordialidade com os vizinhos, afastando a confrontação.

Isto se explica exatamente com referência ao sistema internacional e ao imperialismo. Nesse sentido, considera-se que Rio Branco teve como objetivo garantir a estabilidade política e institucional da América do Sul, evitando agressões extracontinentais. Exemplo disto é seu empenho pela resolução das questões fronteiriças, foco de conflitos entre os Estados. Mais que isto, considera-se que a posição do Brasil como garante da paz no subcontinente foi entrevista por Rio Branco como parte de sua política de prestígio. Com isto, facilitar-se-ia a projeção do país ao nível das grandes potências. Neste ponto, grande valia teve a aproximação com os Estados Unidos. 0 endosso do Corolário Roosevelt pelo chanceler era um meio de dissuadir agressões europeias, como ilustra o caso Panther, elevando o poder do Brasil, em associação com uma potência maior. 
Quanto ao subsistema sul-americano, possível é afirmar-se que iniciativas como o rearmamento naval, defendido por Rio Branco, foram interpretadas na Argentina como sintomas de uma possível agressão ao país. Ora, considera-se que estavam voltadas para o robustecimento do Brasil frente ao sistema internacional, tendo propósitos defensivos e fazendo parte da política de prestígio de Paranhos. Saliente-se, em suma, que a estabilidade da América do Sul e a prevenção de conflitos com os vizinhos eram pressupostos para, a um só tempo, desestimular agressões extracontinentais, baseadas na suposta ingovernabilidade dos países da região, e projetar o Brasil no cenário internacional, mediante a elevação de seu prestígio.

\section{Referências}

ALMEIDA, Paulo Roberto de. Formação da diplomacia econômica no Brasil: as relações econômicas internacionais no Império. São Paulo: Editora SENAC; Brasília: FUNAG, 2001.

ARON, Raymond. Paz e guerra entre as nações. 2. ed. Brasília: Editora Universidade de Brasília, 1986.

BANDEIRA, Luiz Alberto Moniz. O barão de Rothschild e a questão do Acre. Revista Brasileira de Política Internacional, v. 43, n.2, p. 150$69,2000$.

. La formación de los Estados en la cuenca del Plata. Buenos Aires: Grupo Editora Norma, 2006.

BUENO, Clodoaldo. A competição alemã no Brasil no início do século XX: o incidente da Panther. Revista Brasileira de Política Internacional, v. 38, n. 1, p. 64-74, 1995.

Política externa da Primeira República: os anos de apogeu (1902 a 1918). São Paulo: Paz e Terra, 2003.

BOMFIM, Manoel. A América Latina: males de origem. Rio de Janeiro: Topbooks, 2005.

BURNS, E. Bradford. As relações internacionais do Brasil durante a Primeira República. In: FAUSTO, Boris (dir.). História geral da 
civilização brasileira. 3. ed., t. 3, v. 2. São Paulo: Difel, 1985, p. 375400.

A aliança não escrita: o Barão do Rio Branco e as relações Brasil - Estados Unidos. Trad. de Sérgio Bath. Rio de Janeiro: EMC, 2003.

CERVO, Amado Luiz; BUENO, Clodoaldo. História da política exterior do Brasil. Brasília: UNB, 2002.

CERVO, Amado Luiz. Inserção internacional: formação dos conceitos brasileiros. São Paulo: Saraiva, 2008

DORATIOTO, Francisco Fernando Monteoliva. A política platina do barão do Rio Branco. Revista Brasileira de política internacional, v. 43, n. 2, p. 130-149, 2000.

DUROSELLE, Jean-Baptiste. Todo Império perecerá: teoria das relações internacionais. Brasília: Editora Universidade de Brasília, 2000.

GARCIA, Eugênio Vargas. Cronologia das relações internacionais do Brasil. Rio de Janeiro: Contraponto, 2005.

HEINSFELD, Adelar. A geopolítica de Rio Branco: as fronteiras nacionais e o isolamento argentino. Joaçaba/SC: UNOESC, 2003.

HOBSBAWM, Eric. A Era dos Impérios. Rio de Janeiro: Paz e Terra, 1988.

LINS, Álvaro. Rio Branco. São Paulo: Companhia Editora Nacional, 1965.

MAGNOLI, Demétrio. 0 Corpo da Pátria: imaginação geográfica e política externa no Brasil (1808-1912). São Paulo: Unesp, Moderna, 1997.

NOGUEIRA, João Pontes; MESSARI, Nizar. Teoria das Relações

Internacionais: correntes e debates. Rio de Janeiro: Elsevier, 2005.

RICUPERO, Rubens. Rio Branco: o Brasil no mundo. Rio de Janeiro: Contraponto, 2000. 
WATSON, Adam. The evolution of international society: a

comparative historical analysis. Londres: Routledge, 1992. 